\title{
THE GEO-SPATIAL APPROACH TO DETECT THE CHANGE IN VEGETATION AND LAND SURFACE TEMPERATURE (LST) AFTER FORMATION OF ROHINGYA SETTLEMENTS IN BANGLADESH
}

\author{
Mahdi Mansur Mahi, Md. Shahriar Sharif, Rhyme Rubayet Rudra, Md. Nazmul Haque* \\ Department of Urban and Regional Planning, Khulna University of Engineering \& Technology, Khulna-9203, \\ Bangladesh
}

\author{
Date received: 17/07/2021 Date accepted: 22/09/2021 \\ *Corresponding authors' emails: nhaque13@urp.kuet.ac.bd; nhaque.kuet13@gmail.com \\ DOI: 10.33736/jcest.3986.2021
}

\begin{abstract}
The goal of this study is to examine the effects of Rohingya Influx specially on vegetation land cover and LST in Teknaf Peninsula, Cox's Bazar, Bangladesh over time. For doing so, the research followed three steps. Firstly, the primary and secondary data were collected from prescribed sources like LANDSAT 8 images from Earth Explorer (USGS) and the Shapefiles were collected from secondary sources. Then, Normalized Difference Vegetation Index (NDVI) and Land Surface Temperature (LST) functions are explored in geospatial environment used to assess the effect of deforestation on the region. Finally, A correlation is shown between LST and NDVI for making a decision on from the environmental perspective. The findings state that, the region around the Rohingya Camps progressively lost its vegetation density as a result of increasing deforestation. According to this analysis, there was $87.87 \%$ vegetation cover in 2013, which gradually decreased before the Rohingya Invasion in 2017. After the incident in 2018, vegetation cover drops to $75.67 \%$. Similarly, area with no vegetation increased more rapidly than others. The outcome showed that the transition in land cover was quicker and more noticeable in recent time. As a result, the LST has been increasing over the years. According to the study, there were around $8.71 \%$ of areas with high temperatures in 2013 , which increased to $36.86 \%$ in 2020 . It indicates that a large quantity of vegetation has been lost as a result of deforestation, and the LST of this region has changed dramatically. Furthermore, data was examined by Union to assess the individual effect from 5 Rohingya camps, and it was discovered that the situation in Teknaf Union is terrible, while the situation in Baharchhara Union is comparably better. Finally, the results of the research encourage an extensive regional environmental policy to eradicate this problem. To recompense the loss of nature govt. and responsible department should take necessary steps like hill conservation or tree plantation.
\end{abstract}

Copyright () 2021 UNIMAS Publisher. This is an open access article distributed under the Creative Commons Attribution-Non-Commercial-Share Alike 4.0 International License which permits unrestricted use, distribution, and reproduction in any medium, provided the original work is properly cited.

Keywords: Rohingya Influx, NDVI, LST, Teknaf Peninsula, Vegetation Cover

\subsection{INTRODUCTION}

Refugee crisis is one of the most severe problems in the world. The impacts of the refugee influx on the host community's climate and natural resource has become an emerging concern in the field of refugee study [1]. Temporary shelters are also set up near ecologically sensitive areas including national forests, forest reserves, and peripheral agriculture areas [2]. Refugees frequently remain for long periods in their host countries, creating a protracted effect on the climate [3]. The Rohingya are a Muslim minority ethnic group in Myanmar's Rakhine State (then Arakan) [4,5]. One of the world's most stateless minorities is the Rohingya and they are facing ruthless cleansing in Myanmar by the Buddhist majority [6]. Significant violence broke out on 25 August 2017 in the state of Rakhine, Myanmar. Since around December 11, 2017, Cox's Bazar district had nearly 860,000 Rohingya refugees. Since August 25, 2017, 655,000 people have arrived [7]. For decades, more than a quarter million of them had been settled in Bangladesh [8]. The Rohingya people, who've been coming across the border from Myanmar into Bangladesh since August 25, 2017, outnumbered the locals in the Ukhiya and Teknaf sub-districts of Cox's Bazar district, as per the 2011 population census [9]. Around a million Muslim Rohingyas are reportedly taking shelter in Bangladesh's Cox Bazar [10]. The majority of residents are based in the Cox's Bazar sub-districts of Teknaf and Ukhiya, a district bordering Myanmar identified as the main border crossing entrance area [11].The 
latest violence wave resulted a large number of Rohingya influx in Bangladesh. Along with camp growth, this huge scale and speed of influx has also degraded the vital habitat of biodiversity and protected forest areas [12].

This influx impacted negatively on the region's ecology and climate [13].The land with forest provides critical shelter for woodland and wetland habitats in the study area. It offers a diverse range of trees as well as it works as a carbon storage [14]. The protected forest with its wildlife in the study area is being degraded and destroyed at a very alarming rate and clear cutting for agriculture, production, and timber logging are the key reasons [13]. This degradation and destruction has the potential to have a detrimental effect on the climate such as soil erosion, water cycle disruption, loss of wildlife habitat [15]. Changes in land cover may also have an effect on carbon storage potential. It also can cause local climate disruption due to diurnal temperature variations, and it would raise the threat of global warming [16]. So, forest cover changes over the period and the factors causing forest cover change should be monitored and documented to protect and conserve forest biodiversity [17]. A massive amount (1355 ha) of land has been occupied for settlement expansion displacing forest area and degrading natural vegetation was found [18]. [19] has also found dramatic change in natural vegetation in Teknaf Sub-district and Teknaf Nature Reserve. In Palong Khali, Whykong and Nhilla Union, a major decline in vegetation was observed between 2017 and 2018, which is very unusual and alarming [6]. Remotely sensed satellite data is commonly used to monitor land cover change and plant health on a local and global scale because of their high spatial resolution, temporal frequency and availability.

The Teknaf Peninsula is a critically important ecological region. The protected Teknaf Nature Reserve is one of Bangladesh's oldest reserved forests [18]. This vegetation plays a vital role in the adaptation and mitigation process of climate change in the region [19]. Wood is collected for cooking and food, and trees are felled to create shelters by refugees $[20,4]$. As a result, the area around the migrant camps changed dramatically. And this migration has a huge impact on the local areas and wildlife too [15].Several studies have also been performed and various forms of environmental degradation have been identified in different areas of the world. Humanitarian disaster for Rohingya refugees [21], land destruction and deforestation in Sudan [22], forest deteriorating in Western Kenya [23], and loss of agriculture in Syria [24] occurred because of Refugee crisis. Lot of studies also performed for Rohingya crisis in Bangladesh. But maximum of them either included only Normalized Difference Vegetation Index (NDVI) based analysis or Land Surface Temperature (LST) based analysis. This paper focuses on both. Maximum studies about Rohingya crisis analyzed data till December 2018. Though Influx was continued till June 2020 [7]. The expansion of the camps did not stop afterwards. And yet the most crucial part is that the shelters are still using forest resources for their settlement materials, fire woods. Studies on Rohingya camps have been carried out, but none of these studies have been done on Rohingya occupied Unions. All of the previous studies addressed four refugee inhabited Unions, but there are five refugee inhabited Unions in Teknaf and Ukhiya Sub-district. [19] Only took into account Teknaf Sub-district and did not study Ukhiya Sub-district, which also hosts a huge number of migrants. Moreover, none of these studies covered the Teknaf-Ukhiya area's (LST). And no relationship with vegetation cover and temperature changes has been shown in any of the previous works. Thus, these research findings reflect only a partial scenario of the Influx in 2017 for the first few months.

This research work aims to close this gap by examining changes in vegetation cover in Palong Khali, Whykong, Teknaf, Nhilla, Baharchhara Unions of Ukhiya and Teknaf Sub-district from 2013 to 2020. And to assess the Land Surface Temperature of the research area over the years along with relationship between vegetation cover and temperature. The analytical timeline is separated into two temporal periods (2013 to 2017) and (2018 to 2020) because the mass influx began in the latter part of 2017. As a result, this temporal split provides a clear grasp of the consequences of influx on vegetation cover change.

\subsection{METHODOLOGY}

\subsection{Study Area}

This analysis was conducted in 5 Unions of Teknaf and Ukhiya Sub-district in Cox's Bazar District of Bangladesh at $20^{\circ} 52^{\prime} 0 " \mathrm{~N}, 92^{\circ} 20^{\prime} 1 " \mathrm{E}$, namely Baharchhara Union, Palong Khali Union, Nhilla Union, Teknaf Union and Whykong Union. A wide area of tropical evergreen and semi-evergreen forest and other vegetation covers both Teknaf and Ukhiya Sub-districts [14]. The Unions were chosen based on the existence of refugee camps. Palong Khali is in the Ukhiya Sub-district, while Whykong, Teknaf, Nhilla, and Baharchhara are in the Teknaf Sub-district [15]. Sub-district, historically known as Upazilla or Thana, is a Bangladeshi administrative region. Essentially, they are districts' sub-units. A county or a borough in a Western country can be compared to their role. Rural upazila's 
are further subdivided into Union council areas for administrative purposes known as Union Parishads in short "Union" [25].

Figure 1 depicts a map of respective Unions and refugee camps. Across the study area, there are around 100 refugee camps located at the Kutupalong-Balukhali Site in Palong Khali, the Unchiprang Site in Whykong, and the Nayapara-Leda Site in Nhilla Union, which are three of the largest refugee locations $[18,26]$.

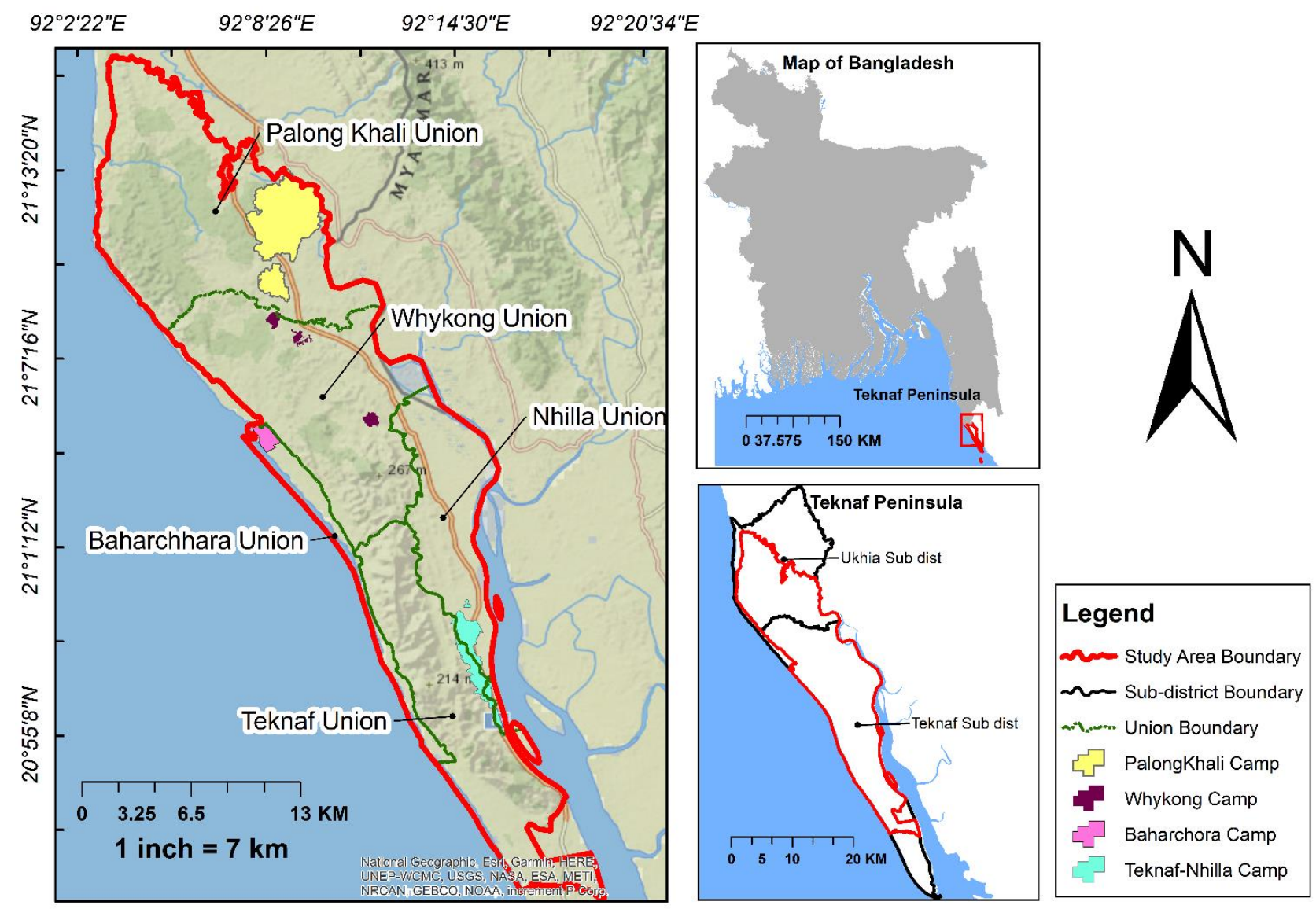

Figure 1 Detail Study Area Map

\subsection{Data Collection and Image Classification}

The study largely depends on primary data gathered from multi-temporal satellite imageries, specifically LANDSAT 8 imageries of specific sensors named Operational Land Imagers and Thermal Infrared Sensor (OLI \& TIRS) captured in the years 2013, 2015, 2017, 2018, and 2020. Data from 2017 was collected prior to the start of the refugee surge, and data from 2018 was collected in March 2018, when the influx was nearly halted. The data for 2020 was gathered to equate the current situation to the peak period of influx in 2018. Although the primary goal of this research is to identify changes in vegetation cover between March 2017 and March 2018, data from previous years as well as data for 2020 have been gathered to correlate with the present situation. The research relied on images from the LANDSAT 8 satellite. These pictures have OLI \& TIRS sensor IDs and a spatial resolution of $30 \mathrm{~m}$. Images weree collected for different years but of the same months. Acquisition Date of these image were 2013-03-14, 2015-03-10, 2017-03-24, 2018-03-02 and 2020-03-01.All of these images have a quality of 9 out of 10 .

First, the image enhancement tool and geoprocessing tools were used to identify and select the research region in order to produce an NDVI Map. Second, LANDSAT satellite images have been adjusted for radiometric and atmospheric errors. Among the most frequent ways for improving LANDSAT images are contrast improvement, saturation, colour, intensity, and density slicing [27]. 


\subsection{Method of Raster Calculation}

The primary goal of this study is to use the Normalized Difference Vegetation Index to measure the changes in vegetation cover in Teknaf and parts of Ukhiya Sub-district. Since this analysis used LANDSAT-8 images, band 5 was assigned to Near Infrared (NIR) and band 4 to Red. The following formula was used to calculate the NDVI [28].

$$
\mathrm{NDVI}=\frac{\text { Band } 5-\text { Band } 4}{\text { Band } 5+\text { Band } 4}
$$

As there are no uniform method of classification of vegetation in remotely sensed data in Bangladesh, the United States Geological Survey's general system of classification has been followed [29]. On which the NDVI value is ranging from -1 to +1 [30]. Based on NDVI values, a total of four levels of ground cover have been identified: $\leq 0.1$ is Non-vegetation, $>0.1$ to $\leq 0.3$ is Sparse Vegetation, $>0.3$ to $\leq 0.5$ is Moderate Vegetation, and $>0.5$ to $\leq 1$ is Dense Vegetation [28]. In general, a dense vegetation area consists a wide variety of trees and plants cover the area in an indeterminate manner. The area must be covered with 70 to $100 \%$ greeneries. For moderate vegetation it is 50 to 70 percent. Sparsely vegetated areas are covered with 10 to 50 percent by trees including steppes, tundra, lichen heath, karstic regions, and scattered high-altitude plants [31].

In addition, the Land Surface Temperature (LST) also derived from those images to show the temperature changes due to deforestation. For calculation of LST the following formula was used [32].

$$
\begin{gathered}
L S T=\frac{\text { Satellite Brightness Temperature }\left(T_{B}\right)}{\left[1+\left(\frac{\text { wavelength of emitted radiance }(\lambda) \times \text { Satellite Brightness Temperature }\left(T_{B}\right)}{C_{2}}\right) \times \ln (\text { emissivity, } e)\right]} \\
C_{2}=\frac{(h \times c)}{S}
\end{gathered}
$$$$
\text { Here, } \mathrm{h}=\text { Plank Constant }
$$$$
\mathrm{c}=\text { Velocity of Light }
$$$$
\mathrm{s}=\text { Boltzmann Constant }(14388 \mu \mathrm{mK})
$$

Again, the general classification scheme used in China was applied because there was no standard Land Surface Temperature classification method for Bangladeshi remotely sensitive data [32]. Table 1 shows the temperature ranges utilized in this study for a better understanding of the LST classes.

Table 1 Land Surface Temperature Classification Table

\begin{tabular}{lll}
\hline Type & Description & Range $\left({ }^{\circ} \mathbf{C}\right)$ \\
\hline LLA & Very Low & $8.87-15.68$ \\
LA & Low & $15.68-18.42$ \\
NA & Normal & $18.42-20.90$ \\
HA & High & $20.90-23.28$ \\
HHA & Very High & $23.28-31.51$ \\
\hline
\end{tabular}

Note: LLA= Very Low, LA= Low, NA= Normal, HA= High, HHA= Very High

\subsection{Accuracy Assessment}

The NDVI precision assessment was classified using the raw satellite images and Google Earth images. Comparison of reference photographs was done during the whole project ( Table 2) by the classified photographs 
following a stratified random sampling procedure with certain random points [33]. IKONOS images were used for 2018 and 2020, and LANDSAT 8 true composite for the rest. As the Rohingya Influx peaked at the beginning of 2018 and stabilized at the end of 2020, high quality $4 \mathrm{~m}$ pictures were utilized for these years for greater accuracy. On contrary A true composite imagery was utilized to analyze the vegetation patterns over time.

Table 2 Sources Used for Accuracy Assessment.

\begin{tabular}{lcccc}
\hline Year & Reference Data & $\begin{array}{c}\text { Spatial } \\
\text { Resolution }\end{array}$ & Date & Source \\
\hline 2013 & LANDSAT 8 true Composite & $30 \mathrm{~m}$ & $2013-03-14$ & earthexplorer.usgs.gov \\
2015 & LANDSAT 8 true Composite & $30 \mathrm{~m}$ & $2015-03-10$ & earthexplorer.usgs.gov \\
2017 & LANDSAT 8 true Composite & $30 \mathrm{~m}$ & $2017-03-24$ & earthexplorer.usgs.gov \\
2018 & IKONOS & $4 \mathrm{~m}$ & $2018-03-02$ & Google Earth \\
2020 & IKONOS & $4 \mathrm{~m}$ & $2020-03-01$ & Google Earth \\
\hline
\end{tabular}

Table 3 depicts the detailed findings of the accuracy assessment. The results showed that the total classification accuracy value ranges between $74.25 \%$ and $92.45 \%$ and Kappa Coefficients vary from 0.77 to 0.88 , which shows high precision. As IKONOS imageries were utilized for accuracy testing in 2018 and 2020, the accuracy is preferable from others. The kappa coefficient for the years 2018 and 2019 is almost 0.9 , since greater resolution makes visual recognition more accurate. The complete analytical method was carried out according to the flowchart in Figure 2.

Table 3 Accuracy Assessment Information

\begin{tabular}{lcc}
\hline Year & $\begin{array}{c}\text { Overall Classification } \\
\text { Accuracy }\end{array}$ & Overall Kappa Statistics \\
\hline 2013 & $74.25 \%$ & 0.77 \\
2015 & $86.10 \%$ & 0.81 \\
2017 & $80.67 \%$ & 0.79 \\
2018 & $90.25 \%$ & 0.87 \\
2020 & $92.45 \%$ & 0.88 \\
\hline
\end{tabular}

The complete analytical method was carried out according to the flowchart in Figure 2.

\subsection{RESULTS}

\subsection{Changes in Vegetation Cover}

The tables reflect the characteristics of vegetation cover changes in sub-district of Teknaf and in the Ukhiya Rohingya camps, i.e., the region around four campsites. The annual variations in vegetation cover are shown in Table 4 


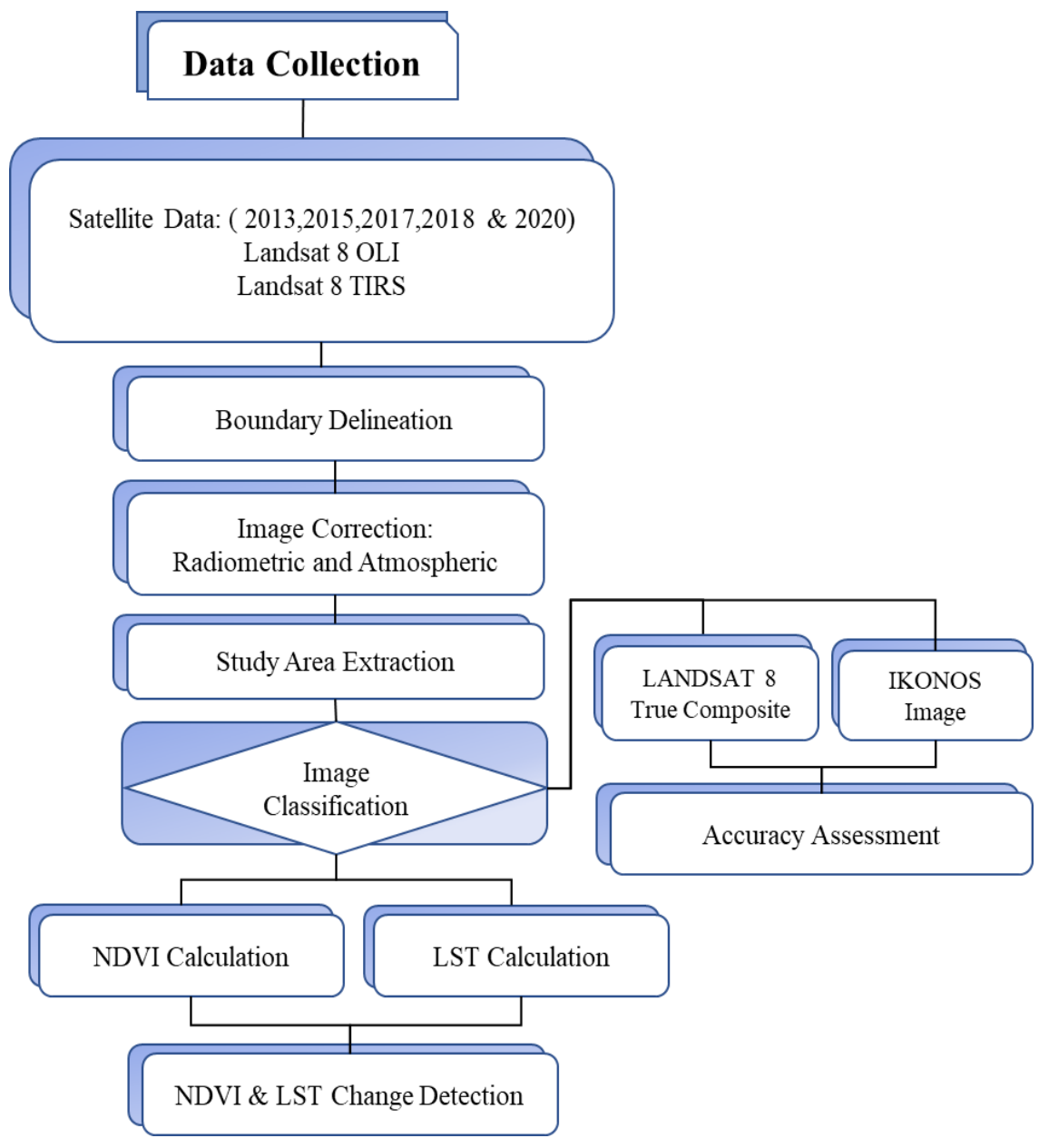

Figure 2 Flowchart of Methodology.

Table 4: Depiction of Vegetation Cover Changes in Respected Years

\begin{tabular}{ccccc}
\hline Year & $\begin{array}{c}\text { Number of Pixels that } \\
\text { Contains Vegetation }\end{array}$ & Area (sq-km) & $\begin{array}{c}\text { Changes in Temporal } \\
\text { Basis (sq-km) }\end{array}$ & \% Change (2013-2020) \\
\hline 2013 & 399469 & 359.52 & - & - \\
2015 & 400774 & 360.69 & +1.11 & $+0.27 \%$ \\
2017 & 404760 & 364.28 & +3.59 & $+10 \%$ \\
2018 & 393096 & 353.78 & -10.50 & $-3 \%$ \\
2020 & 378026 & 340.22 & -13.56 & $-4 \%$ \\
\hline
\end{tabular}

Note: '+' and '-' sign indicates increasing and decreasing respectively 
This timeframe study reveals that vegetation cover in this region has changed drastically. As we see those years before Rohingya Influx, Vegetation Cover is increased although in a small quantity but after that incident it is decreased in an unbelievable amount. As seen in Figure 3. For better understanding Union-wise vegetations are classified separately in Table 5.
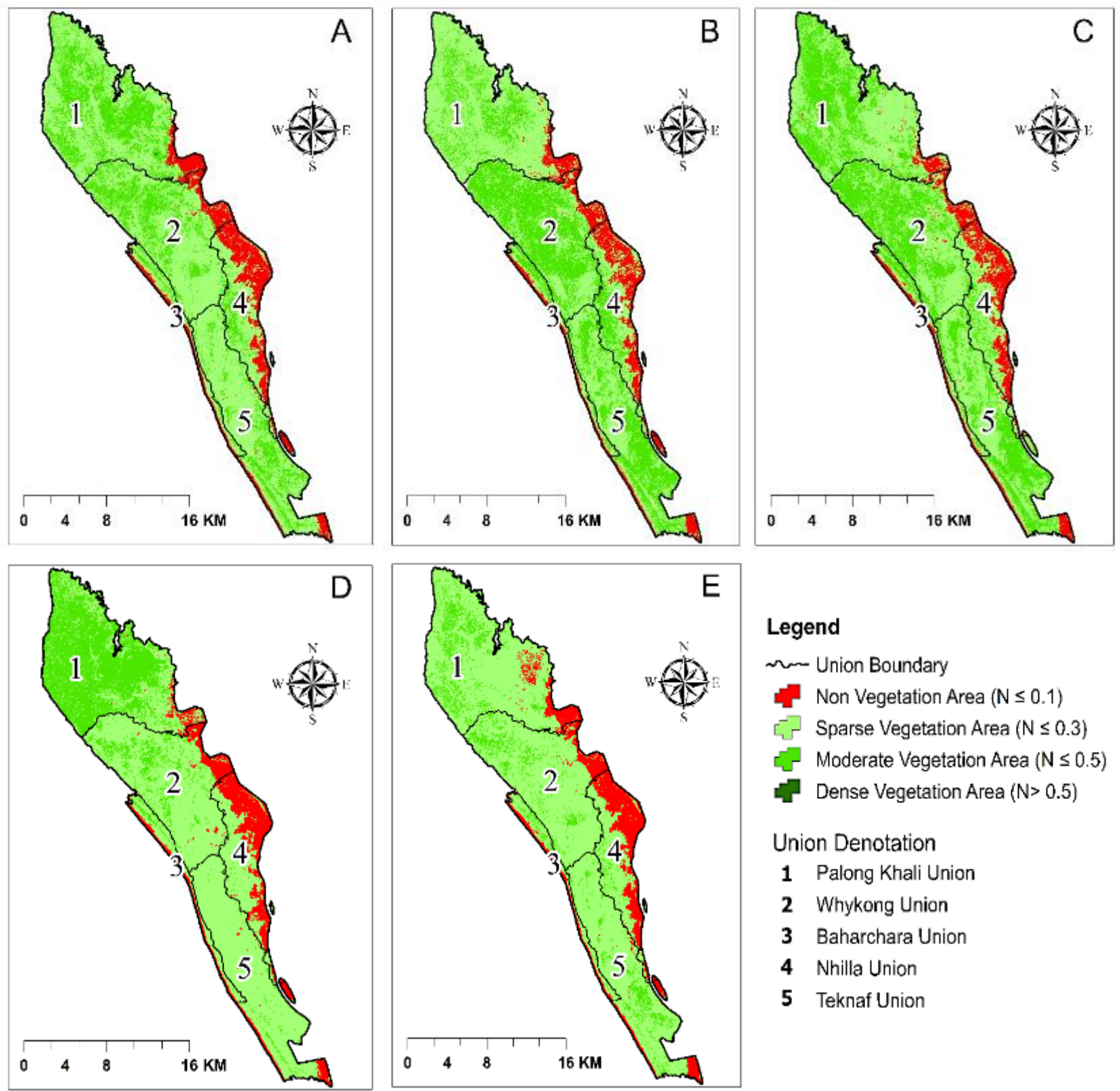

\section{Legend}

ح Union Boundary

Non Vegetation Area $(\mathrm{N} \leq 0.1)$

Sparse Vegetation Area $(\mathrm{N} \leq 0.3)$

Moderate Vegetation Area $(\mathrm{N} \leq 0.5)$

Dense Vegetation Area $(\mathrm{N}>0.5)$

\section{Union Denotation}

1 Palong Khali Union

2 Whykong Union

3 Baharchara Union

4 Nhilla Union

5 Teknaf Union

Figure 3 Normalized Difference Vegetation Index map of Teknaf Peninsula (A) Year 2013 (B) Year 2015 (C) Year 2017 (D) Year 2018 (E) Year 2020 
Table 5 Union Wise Vegetation Density Data

\begin{tabular}{|c|c|c|c|c|c|c|c|}
\hline \multirow{2}{*}{$\begin{array}{l}\text { Vegetation } \\
\text { Cover Class }\end{array}$} & \multicolumn{5}{|c|}{ Area $(\mathbf{s q}-\mathbf{k m})$} & \multirow{2}{*}{$\begin{array}{c}\text { \% Change } \\
\text { (2013- } \\
\text { 2018) }\end{array}$} & \multirow{2}{*}{$\begin{array}{c}\text { \% Change } \\
(2018- \\
2020)\end{array}$} \\
\hline & 2013 & 2015 & 2017 & 2018 & 2020 & & \\
\hline \multicolumn{8}{|l|}{ Teknaf Union } \\
\hline No vegetation & 6.01 & 5.49 & 5.31 & 6.37 & 10.16 & -5.84 & -59.57 \\
\hline Sparse vegetation & 80.98 & 64.01 & 45.10 & 72.81 & 49.18 & +10.08 & +32.45 \\
\hline Moderate Vegetation & 1.93 & 19.44 & 38.51 & 9.75 & 29.59 & -403.62 & -203.50 \\
\hline Dense vegetation & 0.01 & & 0.01 & 0.01 & 0.00 & +7.69 & +25 \\
\hline \multicolumn{8}{|l|}{ Baharchhara Union } \\
\hline No vegetation & 5.63 & 5.85 & 5.72 & 5.97 & 10.96 & -6.12 & -83.74 \\
\hline Sparse vegetation & 11.97 & 9.78 & 7.81 & 11.06 & 8.10 & +7.57 & +26.77 \\
\hline Moderate Vegetation & 1.48 & 3.45 & 5.55 & 2.05 & 0.03 & -38.21 & +98.38 \\
\hline Dense vegetation & 0.00 & & 0.00 & 0.00 & 0.00 & +72.72 & +66.66 \\
\hline \multicolumn{8}{|l|}{ Nhilla Union } \\
\hline No vegetation & 25.74 & 23.18 & 20.27 & 26.37 & 26.70 & -2.53 & -1.17 \\
\hline Sparse vegetation & 29.25 & 26.50 & 25.10 & 27.21 & 28.47 & +6.99 & -4.66 \\
\hline Moderate Vegetation & 0.56 & 5.88 & 10.19 & 1.96 & 5.79 & -245.41 & +79.70 \\
\hline Dense vegetation & 0.01 & 0.00 & 0.00 & 0.00 & & +76.47 & +98 \\
\hline \multicolumn{8}{|l|}{ Whykong Union } \\
\hline No vegetation & 8.18 & 7.42 & 6.38 & 7.51 & 5.86 & +8.17 & +21.96 \\
\hline Sparse vegetation & 85.36 & 68.99 & 38.20 & 88.16 & 56.27 & -3.28 & +36.17 \\
\hline Moderate Vegetation & 15.23 & 32.36 & 64.19 & 13.08 & 46.63 & +14.08 & -256.31 \\
\hline Dense vegetation & 0.01 & 0.01 & 0.01 & 0.02 & 0.02 & -141.66 & 20.68 \\
\hline \multicolumn{8}{|l|}{ Palong Khali Union } \\
\hline No vegetation & 4.04 & 6.57 & 6.90 & 9.17 & 4.50 & -126.82 & +50.91 \\
\hline Sparse vegetation & 42.08 & 76.67 & 101.56 & 107.04 & 81.00 & -154.38 & +24.32 \\
\hline Moderate Vegetation & 90.61 & 53.40 & 28.23 & 20.53 & 51.21 & +77.31 & -149.20 \\
\hline Dense vegetation & 0.03 & 0.11 & 0.05 & 0.01 & 0.04 & +50 & -150 \\
\hline
\end{tabular}

Note: '+' and '-' sign indicates increasing and decreasing respectively 
Table 5 shows that before the Rohingya Invasion, the vegetation density was lowered but the quantity remained the same, while afterward, both the amount and density were modified. In 2013, around 97\% was covered by vegetation, which remained $93 \%$ in 2020 . In a seven-year period, around $4 \%$ of the vegetation gets retained. Among them the badly affected area is Teknaf Union where moderate vegetation lose occurred in almost 4 times in year 2013 to 2018 period, which slightly lessen in year 2018 to 2020 time period due to Rohingya shifting to another camp [18] while Baharchhara Union is in comparatively better condition where about $6 \%$ of bare land increased and about $38.21 \%$ of dense vegetation area is destroyed which is less than that of Nhilla Union as here about 2.45 times of moderately vegetated area of year 2013 is vanished in year 2018. According to analysis, bare land increased at an alarming rate at the Palong Khali Union, in year 2020 as it more than 1.26 times that of year 2013. In Whykong Union the affected type is dense vegetation. More than 1.4 times of the vegetation of the year 2013 is destroyed due to this event. If year 2018 to 2020 period is discussed then it is seen that almost in all camp, the moderate vegetated area is destroyed due to habitat and fuel purpose [26]. In Teknaf it is about 2 times and in Palong Khali and Whykong it is more than 1.5 times of the vegetation of year 2018. The effect of vegetation reduction increases the Land Surface Temperature as shown in Figure 4.

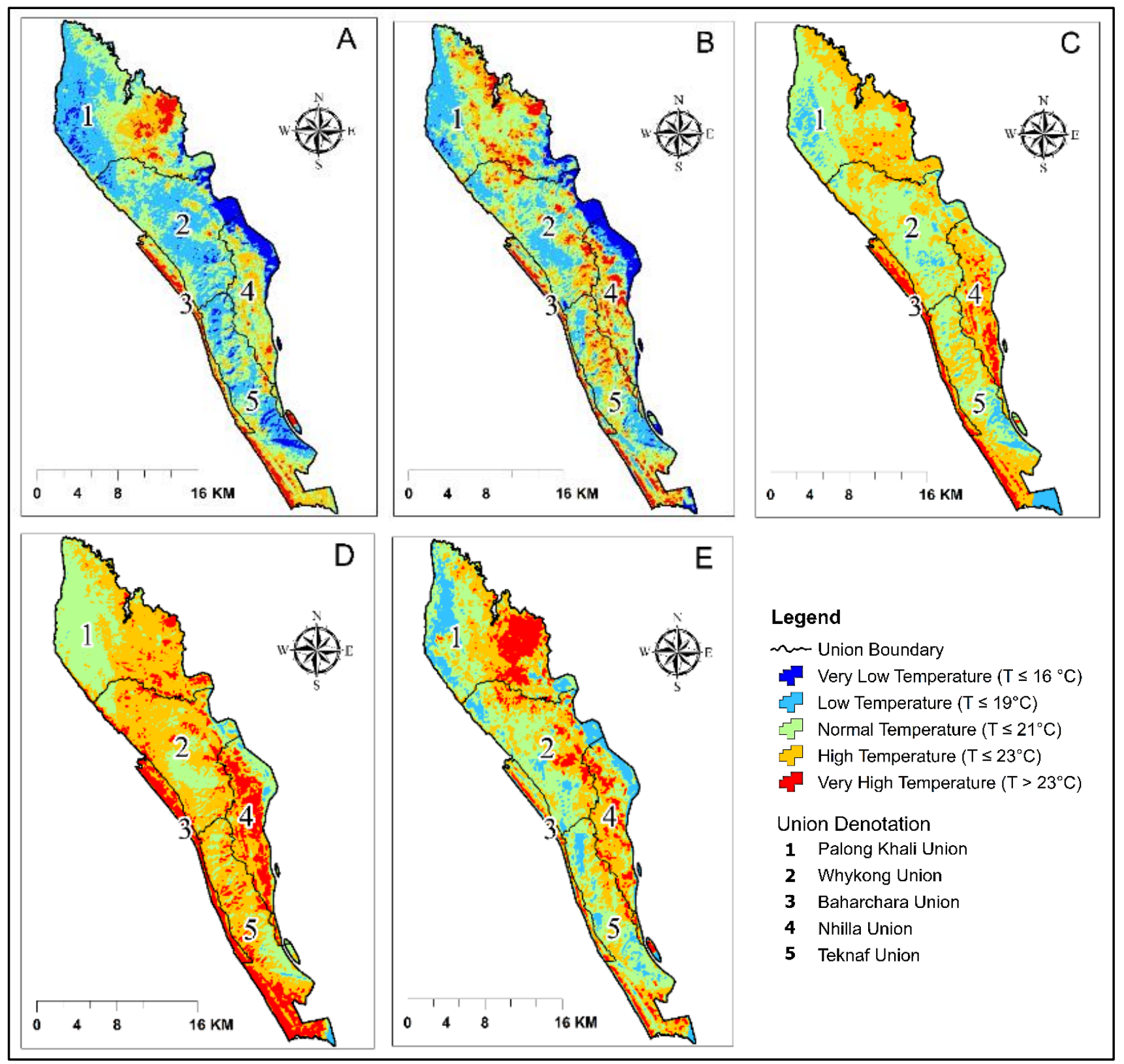

Figure 4: Land Surface Temperature map of Teknaf Peninsula (A) Year 2013 (B) Year 2015 (C) Year 2017 (D) Year 2018 (E) Year 2020 


\subsection{The LST Scenario}

Figure 5 illustrates the temperature changes of areas over the years from 2013 to 2020. It is found that in 2013, about $20 \mathrm{sq}-\mathrm{km}$ area experienced temperature higher than $23^{\circ} \mathbf{C}$ classified as very high. It increased about $40 \mathrm{sq}-$ $\mathrm{km}$ in 2015. But the numbers dropped down in 2017 to $24 \mathrm{sq}-\mathrm{km}$. Surprisingly, in 2018 it increased to $72 \mathrm{sq}-\mathrm{km}$ which is quite unnatural.

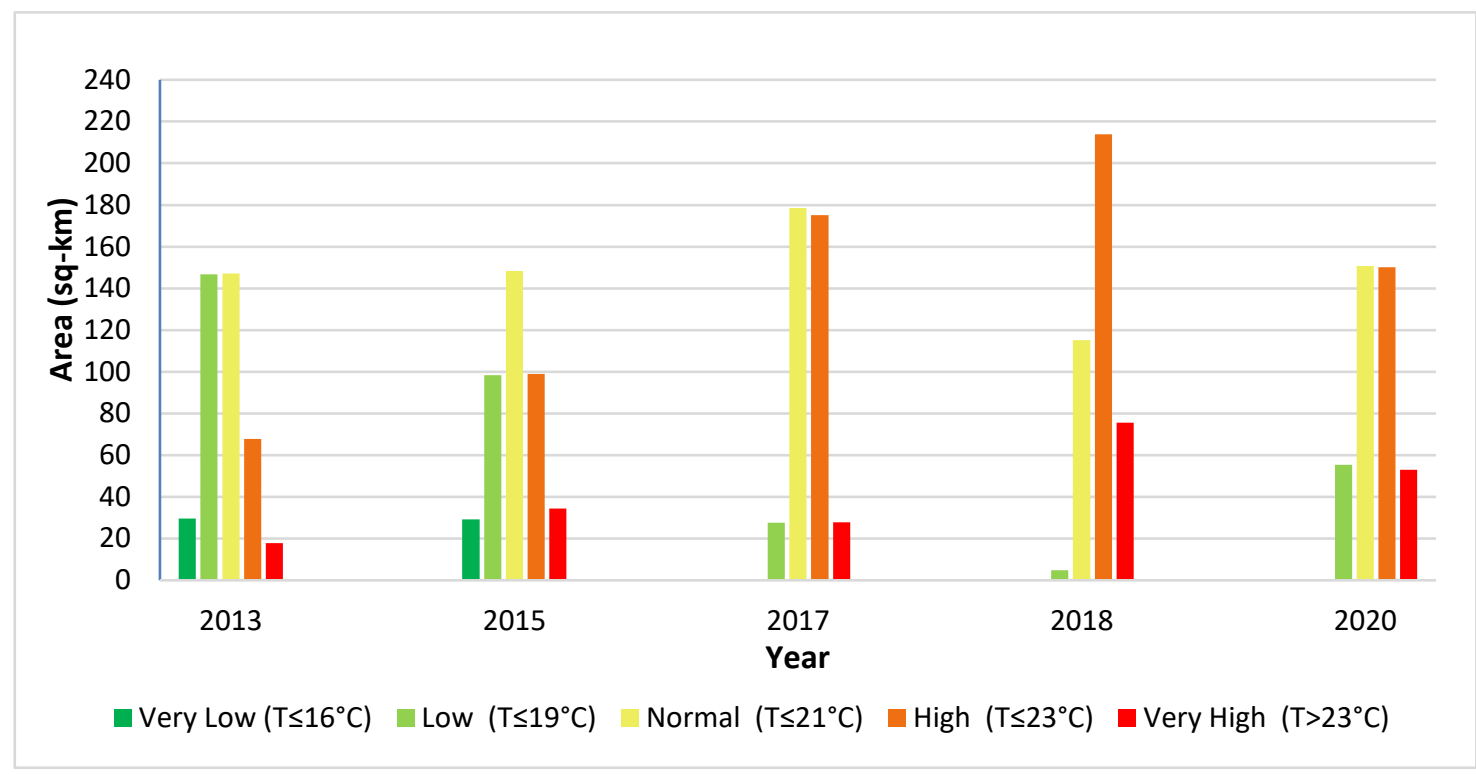

Figure 5: LST comparisons over the years.

Finally, in 2020 the numbers dropped down a bit to $52 \mathrm{sq}-\mathrm{km}$. Same kind of occurrences can be seen in the class of high temperature which is equal or below than $23^{\circ} \mathrm{C}$. As a result, it is apparent that the rapid rate of deforestation has resulted in a considerable increase in land surface temperature in the investigated region.

\subsection{Correlation Between Vegetation Cover and Temperature}

The graph below (Figure 6) demonstrates the relationship between yearly vegetation cover and its influence on temperature. If the Significance (p-value) is less than alpha (0.05), it can be said that the model is significant. Here in Table 6, the p-value is 0.0211 which is smaller than alpha (0.05) and the value of $F$ is 0.1665 . On the other hand, the value of $\mathrm{R}$ square is 0.5261 (52.61\%) with the $\mathrm{p}$ value of 0.0211 which is less than 0.05 .

Table 6 Table of Significance

\begin{tabular}{lcccccccc}
\hline & Coefficients & $\begin{array}{c}\text { Standard } \\
\text { Error }\end{array}$ & t Stat & P-value & $\begin{array}{c}\text { Lower } \\
\mathbf{9 5 \%}\end{array}$ & $\begin{array}{c}\text { Upper } \\
\mathbf{9 5 \%}\end{array}$ & $\begin{array}{c}\text { Lower } \\
\mathbf{9 5 . 0 \%}\end{array}$ & $\begin{array}{c}\text { Upper } \\
\mathbf{9 5 . 0 \%}\end{array}$ \\
\hline Intercept & 0.0985 & 0.3136 & 0.3141 & 0.0211 & -0.8991 & 1.0965 & -0.8994 & 1.0965 \\
\hline X Variable 1 & 0.0027 & 0.0067 & 0.4080 & 0.0412 & -0.0183 & 0.0242 & -0.0187 & 0.0242 \\
\hline
\end{tabular}

Here (Table 6), the slope for level of rejection sensibility is $b=0.0027$ and $a=0.0985$ is the new constant line that is the line intercept. So, the following linear regression equation is

$$
\begin{gathered}
Y=a+b X \\
Y=0.0985+0.0027 X
\end{gathered}
$$




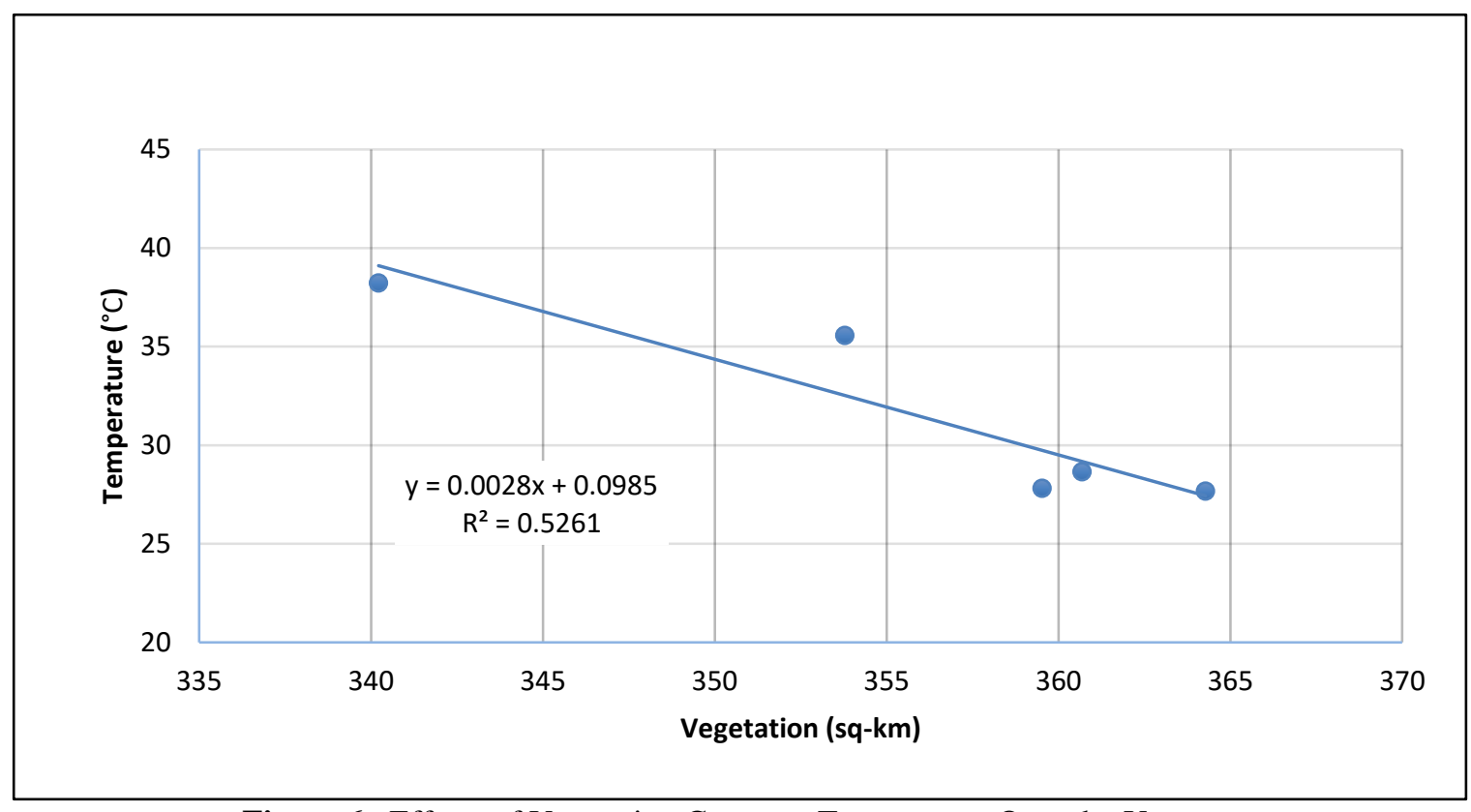

Figure 6: Effects of Vegetation Cover on Temperature Over the Years

Linear regression has been used to evaluate the strength of the relation between variables. This is demonstrated by the fitted line plot, which graphs the connection between vegetation cover and temperature where temperature is dependent on vegetation cover (Figure 6). Here $\mathrm{R}^{2}$ value of 0.5261 indicates that the vegetation cover can explain $52.61 \%$ of the variation in Land Surface Temperature. $\mathrm{R}^{2}$ value of 0.5261 also indicates that temperature is significantly related to vegetation cover. With the increase of vegetation cover temperature decreases.

So, the model explains that there is a variability of the response data around its mean. After analyzing the facts, it can be said that there is a moderate correlation between temperature and vegetation cover where, vegetation cover is independent and temperature is a dependent variable. Results show that rise of the temperature is dependent upon vegetation index. Due to the dramatic fall of vegetation over the year temperature level increased.

\subsection{DISCUSSION}

From the past 50 years, the study area i.e., Unions of Teknaf and Ukhiya Sub-districts are covered with a huge biodiversity and Vegetation cover [19].Normalized Difference Vegetation Index (NDVI) and Land Surface Temperature (LST) are used to assess the effect of deforestation on the region Figure 3 shows that majority of the research area's terrain was occupied with plants in 2013. The coverage of vegetation has substantially grown with the image showing peak vegetation density over the study region in year 2017. Vegetation coverage along Myanmar's border and Rohingya cams have dropped in the following two years (2018 to 2020). This can be attributed to the combustion of wood by the migrants to satisfy their desire for fuel. In this situation a rapid and quick arrival of migrants occurred in August 2017 and the host authorities were utterly unprepared to provide sustainable accommodation that would cause less environmental impact. A substantial quantity of forest cover has been cut off to accommodate the enormous number of migrants.

Figure 3 shows that in 2020 Palong-Khali has witnessed a substantial increase in non-vegetation area compared to prior years, as well as a reduction in vegetation density as the vegetation colors have changed from deep green to light green. Whykong and Nhilla Union demonstrated a decrease in vegetation density in 2020 as compared to earlier years. Vegetation deterioration happened largely in two different ways, certain parts of the woods were bulldozed in order to create refugee camps and immigrants are chopping down existing natural vegetation near their settlements in order to obtain domestic fuel. The pattern described here, however, reveals that the area is undergoing significant land change with deforestation because of the fast growth and related actions of the refuges [18]. The NDVI categorization results therefore demonstrate a decrease in dense vegetation and increase in moderate and sparse vegetation in some Unions. Although some studies imply that migrants have removed 4000 acres of forests [34,35]. Since 2013, an estimated 19 square kilometers (4695 acres) of vegetation cover has been destroyed in five Rohingya-occupied Unions, according to our research based on satellite images.[19] Found a significant shift in vegetation cover in the year 2017 when comparing the years 2014 to 2017. In 2017, total 
vegetation cover fell by 1284.48 hectares. According to our findings, the vegetation cover loss in 2017 is roughly 10.50 square kilometers (1050 hectares) in our studied area. However, in just 2 years (2018 to 2020), about 13.56 square kilometers of vegetation were destroyed (Table 4) The effect of vegetation decrease has led to an increase in land surface temperature as indicated in Figure 4. In Figure 5 It is found that in 2013, the area of low and normal temperature is dominant whereas in 2018 the area of high to very high temperature is dominant. In recent condition (year 2020), the high temperature remains dominant. Indicating gradual rise of surface temperature regarding temporal basis. Instead of causing a negative effect from fast refugee influxes and settlements, this large loss in vegetation cannot be a natural event in any regard. Such quick wooded destruction may generate sustainability challenges in the region since many of the forest re-establishment camps were established in or nearby natural elephant pathways that have already triggered a number of conflicts between Rohingya and elephants.

\subsection{CONCLUSIONS}

The NDVI classification results suggest that in the years between 2017 and 2018, nearly 10.5 sq-km of vegetation decreased in Palong Khali, Whykong and Nhilla Union, while in Whykong, Nhilla and Baharchhara Union more than $13.56 \mathrm{sq}-\mathrm{km}$ of vegetation decreased during the year 2018 to 2020. Reduction to such an enormous vegetation degree in just two years is unprecedented, implying very serious impacts on vegetation cover of the refugee migration and the extension of camps. The refugee influx, however, was an inevitable humanitarian tragedy. It is very difficult to uphold environmental protection during an emergency where human lives are in a precarious state, rather than addressing an acute humanitarian crisis. But some steps can be taken to reduce the loss of nature, as, planting trees is the first and foremost step Reforestation is the most cost-effective way to prevent increase of temperature and decrease of vegetations. Restoring seagrasses can help to increase vegetation and lower temperature. Boosting the use of agricultural cover crops could help to temperature reduction and increase of vegetation. Setting a price on carbon emission can lower temperature. Protecting forests can help with both purposes. Sun, wind and biomass, renewable fuels can be helpful for lowering temperatures. Encouraging better use of natural resources, end major deforestation, promote recycling also helps a lot. The investment needed to reverse land degradation to prevent warming and this investment might help to plant more trees. Agriculture must be more strongly connected to climate solutions. mangroves and peatlands should be maintained and protected properly. biological diversity should be maintained.

\section{Conflict of Interests}

The authors declare that there is no conflict of interests regarding the publication of this paper

\section{Acknowledgement}

The Earth Explorer -USGS was credited as the source of satellite imagery by the authors. Those who directly and indirectly encouraged the writers have been acknowledged. The editorial team is also thanked by the authors.

\section{References}

[1] N. Xypolytas, "The refugee crisis as a preparation stage for future exclusion," Int. J. Sociol. Soc. Policy, vol. 38, no. 7-8, pp. 637-650, 2018, doi: 10.1108/ijssp-11-2017-0149.

[2] M. M. Hassan, A. C. Smith, K. Walker, M. K. Rahman, and J. Southworth, "Rohingya Refugee Crisis and Forest Cover Change in Teknaf, Bangladesh,” Remote Sensing , vol. 10, no. 5. 2018, doi: 10.3390/rs10050689.

[3] "The Impact of Refugees on the Environment and Appropriate Responses - Humanitarian Practice Network." https://odihpn.org/magazine/the-impact-of-refugees-on-the-environment-and-appropriate-responses/ (accessed May 04, 2021).

[4] M. Tani and M. A. Rahman, "Deforestation in the Teknaf Peninsula of Bangladesh: A study of political ecology," Deforestation Teknaf Penins. Bangladesh A Study Polit. Ecol., pp. 1-204, 2017, doi: 10.1007/978-981-10-5475-4.

[5] H. K. Mohajan, “The Rohingya Muslims in Myanmar are Victim of Genocide!,” ABC J. Adv. Res., vol. 7, no. 2, pp. 95-108, 2018, doi: 10.18034/abcjar.v7i2.82.

[6] A. H. Milton et al., "Trapped in statelessness: Rohingya refugees in Bangladesh," Int. J. Environ. Res. Public Health, vol. 14, no. 8, pp. 1-8, 2017, doi: 10.3390/ijerph14080942.

[7] OCHA, "United Nations Office Humanitarian Affairs Annual Report 2017 Ocha Thanks Our Donors for Their Generous Support To Our Activities in 2017," 2017.

[8] "ISCG Situation Report: Rohingya Refugee Crisis, Cox’s Bazar - 25 March 2018 - Bangladesh | ReliefWeb." https://reliefweb.int/report/bangladesh/iscg-situation-report-rohingya-refugee-crisis-cox-s-bazar-25-march-2018 
(accessed May 04, 2021).

[9] J. Leider, Rohingya: The History of a Muslim Identity in Myanmar, no. April. 2018.

[10] "ISCG Situation Report: Rohingya Refugee Crisis, Cox's Bazar | 1 November 2018 (covering 9-29 October) Bangladesh | ReliefWeb.” https://reliefweb.int/report/bangladesh/iscg-situation-report-rohingya-refugee-crisis-cox-sbazar-1-november-2018-covering (accessed Sep. 16, 2021).

[11] "Bangladesh | Needs and Population Monitoring: Undocumented Myanmar Nationals in Teknaf and Ukhia, Cox's Bazar - July 2017 | Round 4 - Bangladesh | ReliefWeb.” https://reliefweb.int/report/bangladesh/bangladesh-needsand-population-monitoring-undocumented-myanmar-nationals-teknaf-2 (accessed Sep. 18, 2021).

[12] M. M. Feeroz, K. Hasan, and M. I. Khalilullah, "Nocturnal Terrestrial Mammals of Teknaf Wildlife Sanctuary , Bangladesh," ZOO's PRINT, vol. XXVII, no. 3, pp. 21-25, 2012.

[13] UNDP and U. N. WOMEN, "Environmental Impact of Rohingya Influx,” no. March, p. 106, 2018.

[14] M. Rahman, M. Islam, and T. Chowdhury, "Change of Vegetation Cover at Rohingya Refugee Occupied Areas in Cox's Bazar District of Bangladesh: Evidence from Remotely Sensed Data,” J. Environ. Sci. Nat. Resour., vol. 11, no. 1-2, pp. 9-16, 2019, doi: 10.3329/jesnr.v11i1-2.43360.

[15] Kudrat-E-khuda, "The impacts and challenges to host country Bangladesh due to sheltering the rohingya refugees," Cogent Soc. Sci., vol. 6, no. 1, pp. 1-16, 2020, doi: 10.1080/23311886.2020.1770943.

[16] H. Tallis, C. Huang, J. Herbohn, K. Holl, S. A. Mukul, and K. A. M. Morshed, "Restoration in the Context of the Rohingya Influx : CGD Policy Paper 148 July 2019,” no. July, 2019.

[17] F. Hossain and D. M. Moniruzzaman, "Environmental change detection through remote sensing technique: A study of Rohingya refugee camp area (Ukhia and Teknaf sub-district), Cox's Bazar, Bangladesh,” Environ. Challenges, vol. 2, no. January, p. 100024, 2021, doi: 10.1016/j.envc.2021.100024.

[18] M. M. Hassan, A. C. Smith, K. Walker, M. K. Rahman, and J. Southworth, "Rohingya refugee crisis and forest cover change in Teknaf, Bangladesh," Remote Sens., vol. 10, no. 5, pp. 1-20, 2018, doi: 10.3390/rs10050689.

[19] S. Imtiaz, "Ecological impact of Rohingya refugees on forest resources: remote sensing analysis of vegetation cover change in Teknaf Peninsula in Bangladesh," Ecocycles, vol. 4, no. 1, pp. 16-19, 2018, doi: 10.19040/ecocycles.v4i1.89.

[20] A. Martin, "Environmental conflict between refugee and host communities," J. Peace Res., vol. 42, no. 3, pp. 329346, 2005, doi: 10.1177/0022343305052015.

[21] B. Ahmed et al., "Humanitarian disaster for Rohingya refugees: impending natural hazards and worsening public health crises," Lancet Glob. Heal., vol. 6, no. 5, pp. e487-e488, 2018, doi: 10.1016/S2214-109X(18)30125-6.

[22] “The Impacts of Refugees on Neighboring Countries," Impacts Refug. Neighboring Ctries., 2010, doi: $10.1596 / 27710$.

[23] A. Braun, S. Lang, and V. Hochschild, "Impact of Refugee Camps on Their Environment A Case Study Using Multi-Temporal SAR Data,” J. Geogr. Environ. Earth Sci. Int., vol. 4, no. 2, pp. 1-17, 2016, doi: 10.9734/jgeesi/2016/22392.

[24] M. F. Müller, J. Yoon, S. M. Gorelick, N. Avisse, and A. Tilmant, "Impact of the Syrian refugee crisis on land use and transboundary freshwater resources," Proc. Natl. Acad. Sci. U. S. A., vol. 113, no. 52, pp. 14932-14937, 2016, doi: $10.1073 /$ pnas.1614342113.

[25] S. K. Sikder, M. Nagarajan, S. Kar, and T. Koetter, "A geospatial approach of downscaling urban energy consumption density in mega-city Dhaka, Bangladesh,” Urban Clim., vol. 26, no. August, pp. 10-30, 2018, doi: 10.1016/j.uclim.2018.08.004.

[26] A. Braun, F. Fakhri, and V. Hochschild, "Refugee camp monitoring and environmental change assessment of Kutupalong, Bangladesh, based on radar imagery of Sentinel-1 and ALOS-2," Remote Sens., vol. 11, no. 17, pp. 134, 2019, doi: 10.3390/rs11172047.

[27] B. Ahmed, M. D. Kamruzzaman, X. Zhu, M. D. Shahinoor Rahman, and K. Choi, "Simulating land cover changes and their impacts on land surface temperature in dhaka, bangladesh," Remote Sens., vol. 5, no. 11, pp. 5969-5998, 2013, doi: 10.3390/rs5115969.

[28] B. Nath, "NDVI An Indicator of Forest Cover Change Detection: A Geospatial Study on Chunati Forest Beat Areas, Chittagong, Bangladesh," J. Image Process. Pattern Recognit. Prog., vol. 2, no. 1, pp. 5-18, Feb. 2015, doi: 10.37591/JOIPPRP.V2I1.261.

[29] USGS, “U . S . Geological Survey Library Classification System,” 2010.

[30] S. R. M. Riad Morshed, M. Abdul Fattah, A. Amin Rimi, and M. Nazmul Haque, "Surface Temperature Dynamics in Response To Land Cover Transformation," J. Civ. Eng. Sci. Technol., vol. 11, no. 2, pp. 94-110, 2020, doi: 10.33736/jcest.2616.2020.

[31] S. M. R. Alam and M. S. Hossain, "A Rule-Based Classification Method for Mapping Saltmarsh Land-Cover in South-Eastern Bangladesh from Landsat-8 OLI," Can. J. Remote Sens., vol. 0, no. 0, pp. 1-25, 2020, doi: 10.1080/07038992.2020.1789852.

[32] Q. Sun, Z. Wu, and J. Tan, "The relationship between land surface temperature and land use/land cover in Guangzhou, China," Environ. Earth Sci., vol. 65, no. 6, pp. 1687-1694, 2012, doi: 10.1007/s12665-011-1145-2.

[33] G. M. Foody, "Status of land cover classification accuracy assessment," Remote Sens. Environ., vol. 80, no. 1, pp. 185-201, 2002, doi: 10.1016/S0034-4257(01)00295-4.

[34] "Destruction of forests by Rohingyas-265211." https://www.daily-sun.com/post/265211/Destruction-of-forests-byRohingyas (accessed Sep. 15, 2021). 
[35] "Bangladesh carving out forest land to shelter desperate Rohingya | Reuters." https://www.reuters.com/article/usmyanmar-rohingya/bangladesh-carving-out-forest-land-to-shelter-desperate-rohingya-idUSKBN1CA0ZN (accessed Sep. 15, 2021). 